\title{
Designer considerations and processes in developing school-based citizen-science curricula for environmental education
}

\section{Anushree Bopardikar, Debra Bernstein \& Susan McKenney}

To cite this article: Anushree Bopardikar, Debra Bernstein \& Susan McKenney (2021):

Designer considerations and processes in developing school-based citizen-science curricula for environmental education, Journal of Biological Education, DOI: 10.1080/00219266.2021.1933134

To link to this article: https://doi.org/10.1080/00219266.2021.1933134

曲 Published online: 15 Jun 2021.

Submit your article to this journal $\widetilde{ }$

Lll Article views: 142

Q View related articles ¿

View Crossmark data \lceil 


\title{
Designer considerations and processes in developing school-based citizen-science curricula for environmental education
}

\author{
Anushree Bopardikar (D) ${ }^{a, b}$, Debra Bernstein (D) and Susan McKenney (D) ${ }^{b}$ \\ aTERC, Center for STEM Teaching and Learning, Berrimah, USA; bUniversity of Twente, ELAN Teacher Development, \\ Enschede, The Netherlands
}

\begin{abstract}
School-based citizen-science can be a powerful means to engage youth in environmental education, yet developing robust science curricula around citizen-science activities is tremendously challenging. Prior research provides limited examples and very little guidance for curriculum designers. To support the designers of school-based citizen-science curricula, this research article presents a participant-observation case study of designer thinking and processes in creating and integrating in-class curriculum with citizen-science fieldwork. Interviews, observations, and documents of designer work aimed at supporting middle school students' learning of climate change were analysed to gain insight into designer thinking, challenges, and resolutions. Findings indicate how designer work evolved through various measures, including appraisal by external advisors, inspiring examples, surveys of teachers' implementations, and written pre-post assessments of student learning throughout the phases of analysis, development, and evaluation of the curriculum. Four key considerations for designing school-based citizen-science curricula emerged from the data: creating the learning environment around the fieldwork; tackling concerns about data quality and utility; making scientist-designed fieldwork engaging to students; and balancing scientific and educational goals. These considerations are discussed in light of relevant literature, and educational implications for design and research are presented.
\end{abstract}

\section{KEYWORDS}

curriculum design; citizenscience; participantobservation; case study

\section{Introduction}

Citizen-science, defined as public participation in organised research efforts, engages the general public in partnering with professional scientists to study environmental change (Dickinson and Bonney 2012). By collecting, submitting, and analysing large quantities of data that are often beyond the resources of routine scientific projects, non-scientists can contribute significantly towards developing scientific knowledge of, and solutions to, problems faced by broader communities (Shah and Martinez 2016). Indeed, citizen-science projects have produced important scientific outcomes (see Bonney et al. 2015 for review).

In addition to scientific goals, citizen-science projects often strive to promote education in environmental science, commonly through curriculum-based projects for the K-12 student and teacher audience (Bonney et al. 2015). This is because schools are essential sites for environmental education (Alkaher and Gan 2020; Cherif 1992), and integrating formal curricula with citizenscience initiatives provides a means to strengthen students' understanding of science and scientific 
inquiry skills through active participation in authentic research (Shah and Martinez 2016). In fact, citizen-science projects are becoming popular globally for improving science education (Bonney et al. 2009; Kelemen-Finan, Scheuch, and Winter 2018; Paige, Hattam, and Daniels 2015), in part because these contexts promote the social construction of knowledge - teachers and students participate as part of a community of practice to inquire into issues of societal importance (Gilbert, Bulte, and Pilot 2011). In partnering with professional scientists, students formulate research questions, and collect, analyse, and communicate data about local or broader environmental issues (Houseal, Abd-El-Khalick, and Destefano 2014; Trautmann et al. 2012).

One environmental issue deserving explicit attention is climate change, and there has been increased interest in recent years towards addressing this issue in science education. This is critical because students show varying degrees of understanding about climate change and its underlying causes (Holmqvist Olander and Olander 2017). To promote climate change education, studies emphasise making information about (global) climate change personally relevant and meaningful to students through local examples and contexts; fostering active participation and interactions with climate scientists; and supporting teachers with resources, such as lesson plans, to teach about climate change (Foss and Ko 2019; Monroe et al. 2019). Yet realising these characteristics in school is easier said than done. Citizen-science approaches can address these needs.

\section{Problem statement}

To implement school-based citizen-science, it is crucial to provide teachers and students with welldesigned curricula. While student-teacher-scientist partnerships offer many benefits, such as high levels of student engagement (McLaughlin et al. 2016), the partnerships are also challenging to implement. For example, scientists are concerned with the validity of scientific research involving student-gathered data, and teachers are concerned with time demands and aligning goals and activities with curriculum standards (Doubler 1997). Hence, designers need to ensure that the quality of the fieldwork and data is maintained to attain important scientific benefits while also focusing on the learning goals to be attained (Shah and Martinez 2016). Moreover, it is difficult to gather meaningful scientific findings over short time periods, but the lack of results risks lowering student interest (Barstow 1997). Thus, whereas student-gathered data can contribute to long-term data sets, it is difficult for students to see clear patterns in the short-term.

The literature to date provides some resources for realising school-based citizen-science learning (e.g. Trautmann et al. 2012). However, curriculum designers still struggle, as they encounter many novel design challenges when integrating formal science curricula with citizen-science. A core challenge is to design for fieldwork that is meaningful and engaging for students, feasible for teachers to implement, and rigorous enough for scientists to incorporate into their research. For example, how might designers equip students with sufficient understanding of curriculummandated concepts and practices to contribute valid and reliable data towards scientific research (Zoellick, Nelson, and Schauffler 2012)? Further, how might students be trained to avoid bias in underreporting or overreporting data, which may have a bearing on the study's intended scientific outcomes (Shah and Martinez 2016)? And at the same time, how might designers balance opportunities for student ownership over fieldwork with adherence to the protocols and requirements of scientific research (Gray, Nicosia, and Jordan 2012)?

The literature lacks precedents of designer thinking, which can provide insights into barriers, actions, and rationales underpinning the actual design work (Howard et al. 2012). What is also lacking is fine-grained information on considerations and processes that shape the evolving logic in designer thinking about how a proposed curriculum would support student learning. Designers rely strongly on their experiences and draw on known precedents of particular designs (Lawson, 2004), but direct experiences with a broad range of citizen-science curriculum precedents are difficult to attain because integrating formal science curricula with citizen-science is a relatively new approach. Specifically, the lack of knowledge about designer thinking poses difficulties in creating feasible and 
meaningful fieldwork experiences, in supporting students' understanding of requisite scientific content, and in supporting teacher knowledge of scientific practices.

Therefore, this research article reports on a study that investigated how designers tackled challenges while developing a middle school citizen-science curriculum on climate change. In so doing, the study also unpacks the considerations and processes that shape designer thinking in responding to emergent challenges. As described next, the study's theoretical framework draws together three salient bodies of work: context-based learning, curriculum representations, and educational design processes.

\section{Theoretical framework}

\section{Context-based learning}

Context-based learning uses problem-based, student-centred practical activities to ensure that learning is meaningful and relevant to the contexts of real-world problems (Rose 2012; Yu, Fan, and Lin 2015). Curricula centred on contexts that are relevant to students' lives can foster coherent understanding of scientific content (Bennett and Holman 2002). Furthermore, the context-based approach has also been used to support science teacher learning in environmental education (Deveci and Karteri 2020). When supporting context-based learning, experts recommend selecting contexts that exemplify key explanatory concepts and that are pertinent to students' lives and more broadly to societal concerns (Gilbert 2006; Gilbert, Bulte, and Pilot 2011). For a citizen-science ecology curriculum, a possible context is formed around investigating climate change phenomena, manifested in vegetation and bird responses. Gilbert and colleagues recommend attending to four main attributes of the context, (setting; background knowledge; behavioural environment; and specific scientific language). Elaborated below, these concepts feature prominently in the present study.

The first two attributes are considerations to which designers need to respond. The setting is a social situation within which students experience a specific context for the subject matter (Gilbert 2006; Gilbert, Bulte, and Pilot 2011). The setting relates to a community of practice, such as one composed of scientists. For a citizen-science curriculum on climate change, for example, the setting involves a community of scientists investigating climate-related phenomena in students' everyday environments and collecting longitudinal data on plants and animals. In engaging with this setting, students and teachers interact with one another and with scientists. The background knowledge attribute can be understood as the general knowledge that students need to participate productively in this setting, such as prior knowledge of statistical concepts for data collection and analyses (Gilbert 2006; Gilbert, Bulte, and Pilot 2011).

Further, designers need to craft the following two attributes in the curriculum. The behavioural environment includes typical tasks in a science domain that address the context and exemplify fundamental scientific concepts (Finkelstein, 2005). Here it is important to think of activities that enable students and teachers to engage in authentic scientific inquiry. For a citizenscience curriculum on climate change, possible activities relate to scientific practices including formulation of questions and hypotheses for fieldwork, and collection and analyses of climaterelated data. The specific language attribute refers to discourse about specific scientific concepts and representations, including graphs and other visuals that are associated with the context (Gilbert 2006; Gilbert, Bulte, and Pilot 2011). Designers should consider ways to help students participate in discourse about specific scientific concepts and practices (for examples of scientific ideas and practices, see science standards described in NGSS Lead States 2013). For instance, citizen-science curricula addressing climate change would include discourse about scientific concepts related to weather and climate.

In this study, the aforementioned attributes serve as an analytical lens to help the researchers understand designer thinking and processes underlying a citizen-science curriculum. The attributes 
are used to interpret the decisions and activities of curriculum designers in supporting students' learning about climate change.

\section{Designing multiple curriculum representations}

Designer attention to context attributes is manifested through different curriculum representations. Building on classic representations of curriculum (Goodlad, Klein, and Tye 1979; van den Akker 2003), this study focusses on three: intended outcomes, envisioned enactment, and written curriculum. Each representation contributes specific elements to the designers' theory of action, which helps them consider the logic behind how a curricular intervention will support student learning. A basic theory of action unpacks the relationships between inputs, processes, and outcomes (McKenney \& Reeves, 2019).

For curriculum deesigners, it concerns how their designed inputs (i.e., the written curriculum), shape classroom enactment (i.e., the implemented learning and teaching activities), and ultimately engender certain results (i.e., especially student learning). They understand that this flow represents how schools experience curricula (see Figure 1, elements in dashed boxes). At the same time, when designers set to out create the curriculum, they consider multiple representations at once, and often map backward from articulating the intended outcomes, to formulating a vision for activity that will help attain those outcomes, to creating materials that will help bring the vision to life (see Figure 1, elements in solid boxes). Designers may proceed with an initial theory of action once potential ideas for the curriculum are in place, and the theory evolves as additional considerations emerge during the design process. Elaborated next, the present study investigates designer thinking and processes aimed at refining each representation for a citizen-science curriculum, as well as aligning and recalibrating the overall theory of action to support student learning.

For designers, the first representation created is often the intended outcomes, which are the student learning objectives to be attained (Thijs and van den Akker 2009). In science curriculum design, these are generally the target scientific concepts and practices that students should comprehend. The intended outcomes may also specify how students should apply their understanding of the concepts and practices to perform specific tasks (Krajcik, McNeill, and Reiser 2008). Common intended outcomes for citizen-science include developing conceptual knowledge and skills of data collection and reporting (Phillips et al. 2018). In view of the intended outcomes, designers can identify phenomena to make the target concepts and practices accessible to students (Krajcik, McNeill, and Reiser 2008), and can identify alternative student conceptions that would be important to address in the written curriculum (Rivet \& Krajcik, 2004).

The second representation is the envisioned enactment, which involves instructional activities to help students and teachers attain the intended outcomes (Thijs and van den Akker 2009). In science curriculum design, the designer vision may include student investigations with driving questions (Edelson and Reiser 2006), a teacher role in facilitating discussions with students (Kolodner et al., 2003), and organisational matters involving student grouping and location of activities (Thijs and

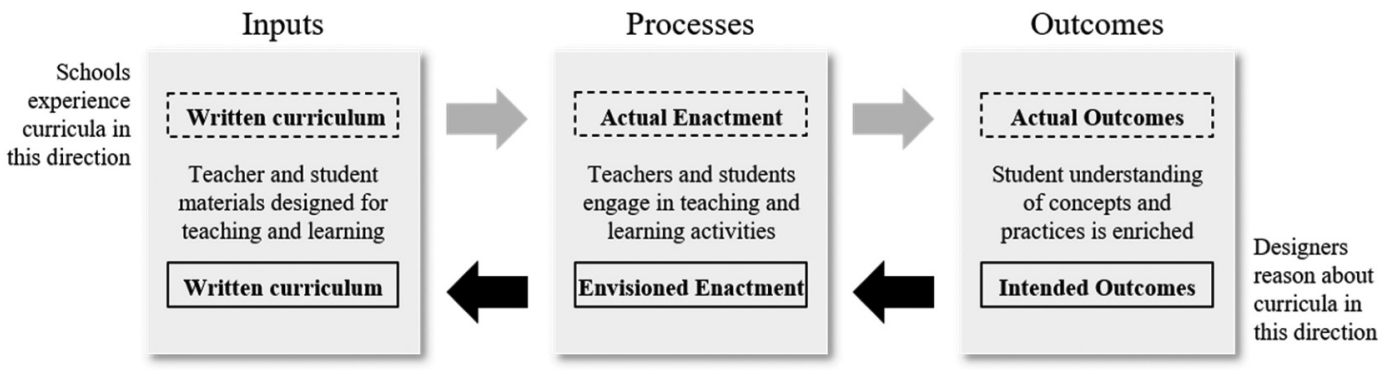

Figure 1. Designer theory of action. 
van den Akker 2009). Examples of citizen-science curricular activities include instruction on generating scientific questions, using particular tools for fieldwork, and analysing and communicating findings in broad communities (Houseal, Abd-El-Khalick, and Destefano 2014). The design of instructional activities influences how deeply students engage with the target scientific concepts and practices (Tekkumru-Kisa, Stein, \& Schunn, 2015).

This study also focuses on how designer ideals are manifested in the third representation, the written curriculum, typically taking the form of print-based and/or digital materials, such as teacher and student guide books (Thijs \& van den Akker 2003). The written curriculum incorporates designer considerations about the context attributes of setting and background knowledge, and contains supports to enact designer vision of the context attributes of behavioural environment and specific scientific language to attain the desired outcomes. In science curriculum design, materials to guide students' investigations contain prompts for planning experimental procedures (Kolodner et al., 2003), analysing data (Songer 2006), generating explanations grounded in evidence and scientific principles (McNeill, Lizotte, Krajcik, \& Marx, 2006), and applying scientific knowledge to open-ended scenarios (Schwartz 2006). Teacher materials present learning objectives and desired student responses, and offer suggestions for demonstrations and investigations (Schwartz 2006). Additionally, tips are offered to lead class discussions (Pareja- Roblin, Schunn, \& McKenney, 2018), and educative elements explain students' typical conceptions (Roseman, Herrmann-Abell, and Koppal 2017), present science content to highlight during instruction (Davis et al. 2014), and provide strategies to enact scientific practices (Bismack et al. 2015).

Examples of materials to enact citizen-science are student journals containing questions to activate prior content knowledge (Harlin et al. 2018); worksheets containing stepwise instructions to support scientific practices (The Globe Program); lesson plans and teacher guides containing inquiry strategies, such as questioning to promote scientific thinking and critique (Trautmann et al. 2012), and fieldwork protocols (The Globe Program). The written curriculum is critical because scientific practices are challenging for students (Edelson and Reiser 2006) as well as for teachers (Zangori, Forbes, and Biggers 2013), and the extent of written support shapes students' understanding of the practices (McNeill et al., 2006; Songer 2006).

\section{Educational design processes}

The above-mentioned curriculum representations come about and evolve through systematic, iterative processes comprising the core phases of analysis, development, and evaluation (McKenney \& Reeves,2019). The overall process typically begins with the analysis phase, which focuses on identifying and understanding the problem (McKenney \& Reeves,2019). In this phase, designers study the existing situation to help fine-tune their ambitions and approaches (McKenney \& Reeves,2019). Common activities include reviewing science curriculum frameworks to explore possible concepts and practices (Krajcik, McNeill, and Reiser 2008; Songer 2006), and existing science curriculum materials to identify opportunities for student learning (Davis et al. 2014). Additionally, they gather data on the needs and context of the target teacher and student populations (Edelson 2002), for example, through surveys conducted with school personnel (McKenney \& Reeves,2019). The resultant insights allow designers to conceptualise the challenge at hand and begin to envision the enactment of teaching and learning, pinpoint overall intended outcomes, and derive initial design requirements and specifications for the written curriculum (McKenney \& Reeves, 2019; Edelson 2002).

Then, the development phase focuses on conceptualising and creating the curriculum (McKenney \& Reeves,2019). In this phase, designers generate fine-grained ideas for the intended outcomes, their vision for enactment, and the written curriculum. They map detailed specifications, and construct and revise prototype representations based on insights from both the preceding phase or (at later stages) following evaluation (McKenney \& Reeves,2019). Principal activities include reviews of prior research and curriculum frameworks to formulate specific learning goals and 
sequences of instructional activities (Krajcik, McNeill, and Reiser 2008; Songer 2006). Designers draw on theory, inspiring examples, and local expertise (McKenney \& Reeves,2019). For example, they seek input from scientists on key scientific facts (Songer 2006) and disciplinary practices (Edelson, Gordin, and Pea 1999). They also prepare matrices to track how scientific concepts are treated in different contexts (Schwartz 2006). This phase enables designers to define measurable intended outcomes (Gustafson and Branch 2002), choose contexts and assemble relevant content (Pilot and Bulte 2006), envision enactment of instructional activities, and prepare materials based on the design specifications (Gustafson and Branch 2002).

Finally, the evaluation phase focuses on empirical testing of the curriculum (McKenney \& Reeves,2019). Designers test the curriculum formatively and summatively, acquiring data to plan subsequent revisions and to gauge the effectiveness of the intervention (Gustafson and Branch 2002). Notable activities include gathering appraisal from external experts or advisory board members (Davis et al. 2014; Schwartz 2006), pilots of initial prototypes, and classroom field tests of more mature versions of the curriculum (McKenney \& Reeves,2019). Designers observe teacher enactment (Davis et al. 2014; Roseman, Herrmann-Abell, and Koppal 2017) and student engagement (Edelson, Gordin, and Pea 1999); gather teacher feedback in person or via surveys about written materials, such as fieldwork protocols (Houseal, Abd-El-Khalick, and Destefano 2014); and assess student learning outcomes (Clarke and Dede 2009). Results from this phase support empirical tuning of the intended outcomes, envisioned enactment, and the written curriculum.

\section{Research goals, significance, and question}

This study responds to calls for designing opportunities and materials to support student and teacher engagement with issues in environmental education, such as climate change (Foss and Ko 2019; Monroe et al. 2019), and for producing rich cases tying designed products directly to designer process (Howard et al. 2012). Therefore, like process-oriented worked examples in other areas (Valero Haro et al. 2019; Van Gog, Paas, and Merriënboer 2004), this study aimed to produce a detailed example of how designers make decisions in creating a school-based citizen-science curriculum and how their decisions shape the evolving theory of action underlying the curricular intervention. The worked example contributes to curriculum design knowledge by elucidating designer rationales and processes for responding to key issues in designing school-based citizenscience curricula. These descriptions, in turn, provide insights to other experienced and novice designers pursuing similar endeavours (Howard et al. 2012). With this aim, the study investigated the following question: In designing school-based citizen-science curriculum, how do designers shape the processes and decisions that contribute to their evolving theory of action over time?

\section{Methods}

\section{Case study approach}

To address the research question, a qualitative interpretive case study (Merriam 1988) was conducted of designer work involved in creating a single school-based citizen-science curriculum. The method was suitable given that the target output was a detailed worked example of designer thinking and processes shaping a curriculum product (Howard et al. 2012). Specifically, the study sought to yield a case of designer thinking and processes to tackle the challenges arising in creating and integrating in-class curriculum with citizen-science fieldwork. To that end, a participantobservation technique was followed to investigate phenomena that are otherwise difficult to capture in depth (Yin 2014): the evolution of designer processes and solutions in response to emergent needs and challenges.

The curriculum was developed at an independent STEM educational research and development organisation in the U.S., in collaboration with ecologists at a local scientific research institution. The 
project aimed to produce an in-classroom curriculum for middle school students (of ages 12-13 years), aligned with science education standards in the U.S. stressing students' understanding of core scientific concepts and practices. Students' learning was framed within a context of investigating climate change as it manifested in their local surroundings.

This curriculum design endeavour was in the service of a pre-existing partnership between the aforementioned ecologists and local schools, and it was intended to scale up to schools and science partners at a distance. The curriculum was crucial to help schools and scientists in the partnership to pursue both educational and scientific goals systematically. It aimed to support students and teachers to contribute data towards research conducted by partner scientists. Hence, the curriculum was aligned with a standardised fieldwork component that had been previously developed by the ecologists in partnership with local schools. For example, students measured leaf length and width, tree height, and canopy cover as observed near their school grounds. These data were intended to complement and contribute towards the ecologists' ongoing, long-term research on studying how ecosystem changes, including those in temperature and vegetation availability, influence the responses of migratory birds, such as the timing of their arrival. In so doing, the studentgathered data were expected to help develop a more complete understanding of how regional ecosystems influence bird behaviour. In addition to the standardised fieldwork, there were opportunities for students to contribute data towards other broader citizen-science repositories, such as the National Phenology Network's nature's notebook (USAPN).

The project also strove to promote students' understanding of key concepts and practices in climate science. The concepts included local bioindicators of global climate change, and the differences between weather, climate, and precipitation. The practices included generating hypotheses, analysing longitudinal data sets, and using specific fieldwork techniques. The project reported significant improvement in students' understanding of specific topics, based on written pre- and post-assessments. For example, $\sim 72 \%$ of the students distinguished satisfactorily between weather and climate on the post-assessment, as opposed to $\sim 42 \%$ on the pre-assessment (Wilcoxon Signed Ranks Test, based on negative ranks: $\mathrm{Z}=-5.253, \mathrm{p}<.0001)$. Similarly, $\sim 79 \%$ of the students provided acceptably accurate or complete answers on the post-assessment in describing the impact of seasons on plant and animal life activities, compared to $\sim 63 \%$ on the pre-assessment $(\mathrm{Z}=-2.336$, $\mathrm{p}=.02$ ). Finally, $\sim 28 \%$ of the students provided accurate answers about possible species responses to climatic warming, in contrast to $\sim 17 \%$ on the pre-assessment $(\mathrm{Z}=-3.467, \mathrm{p}=.001)$.

\section{Participants and research setting}

A combination of purposeful and referral sampling was used to recruit designers of the curriculum project for this study. The project leader served as an informant to guide sampling choices (Yin 2014) based on the designers' roles on the project. The project leader and an additional curriculum writer from the educational research organisation were selected because they had contributed primarily to writing the curriculum materials. They had training in ecology and prior experience with school science curriculum development. The lead ecologist and an additional ecologist from the scientific research institution were selected because they had contributed primarily to the citizen-science agenda and the fieldwork component. The ecologists also had prior experience in leading activities for environmental education. All participants signed informed consent documents prior to the start of the study. The researchers were not involved with the curriculum project prior to this research study, but they were granted access to relevant project documents, conversations with the participants, and in-depth participant-observation research of the curriculum design process and resultant materials. ${ }^{1}$ 


\section{Data sources}

Multiple sources of evidence were used to triangulate data and produce credible and confirmable findings, as per recommendations in qualitative research (Guba 1981; Yin 2014). Data consisted of researcher-generated notes of the designers' weekly meetings and of one fieldwork enactment at a school site, and written feedback reports discussed with designers about their curriculum materials and design processes. The data set also included documentation produced by the designers (planning documents and memos; email communication; drafts of written curriculum; curriculum project grant proposal; teacher surveys; annual progress reports to the funding agency; and written pre-post assessments of student learning). Finally, there were five transcripts of designer interviews (two interviews with the project leader and an interview each with the remaining three participants).

\section{Procedures}

The first author served as participant-observer and was 'immersed' (Emerson, Fretz, and Shaw 1995) in the team's routine design work. Her involvement began in the middle of the first year of the project, as the team was preparing for the first implementation. The data collection ended in the second year of the project, as the team continued preparing for the second implementation (see Figure 2). Following recommendations from the curriculum project leader, the researcher observed the designers' evolving theory of action behind the curriculum representations and shared her interpretations of the project's intended outcomes of students' learning, their vision for enactment, and the written curriculum as part of a team reflection activity. The overall procedure involved using various data sources in an overlapping manner to generate complementary and dependable findings (Guba 1981).

As an observer, the researcher attended weekly team meetings and an enactment of the standardised fieldwork component at a school site. Casual direct observations (Yin 2014) of the designers' processes and decisions in crafting and aligning the different curriculum representations were made over 17 months from January 2015 - May 2016. This prolonged engagement (Guba 1981) allowed

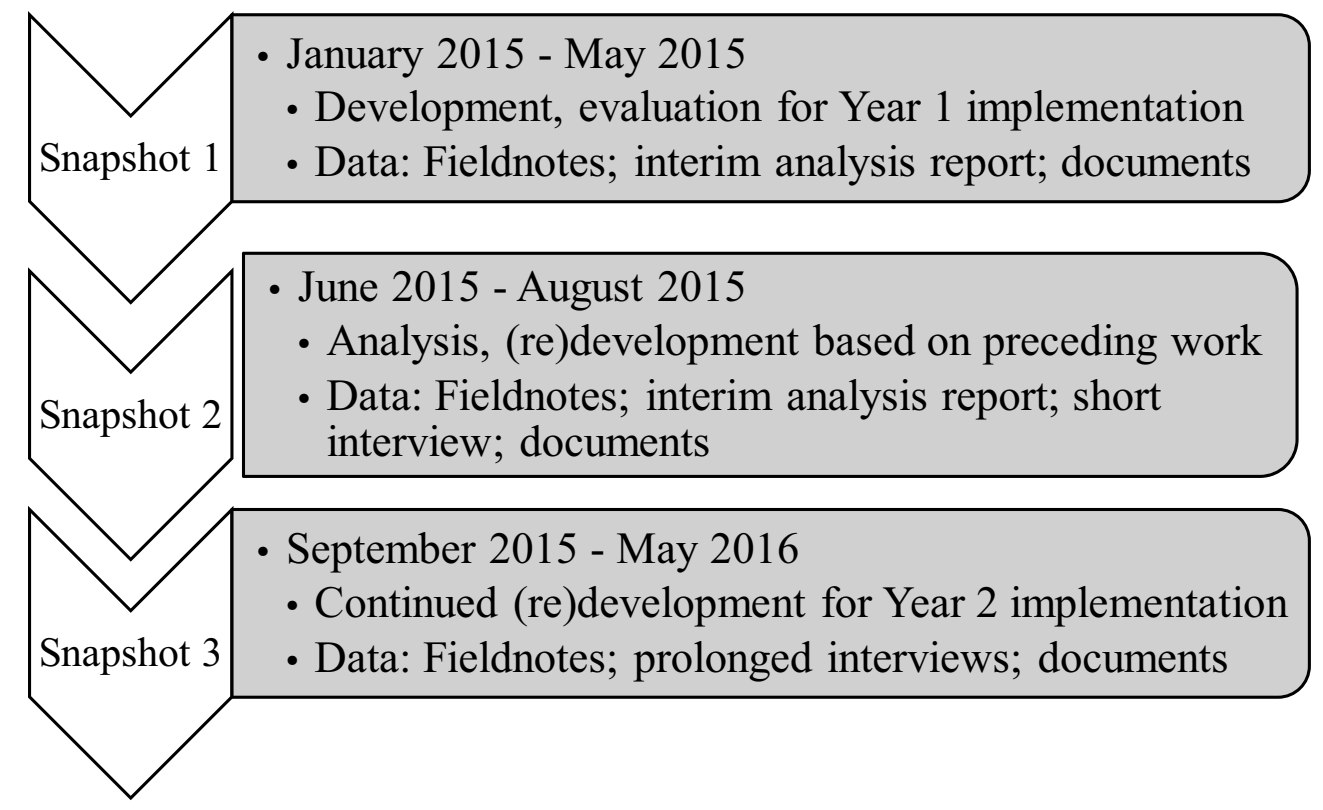

Figure 2. Snapshots, time periods, phases of the curriculum design work, and data sources of study. 
researchers to study the evolution of designers' work, culminating in three 'snapshots' (see Figure 2). Fieldnotes were generally written immediately after the observed events to capture complexities of designer work (see Emerson, Fretz, and Shaw 1995). The researcher also catalogued project documentation produced by the designers.

As a participant, the researcher shared with the designers two reports of interim analysis detailing their theory of action behind the curriculum representations, describing the associated design processes through which those representations were evolving, and noting possible next steps. The reports were based on interpretations arising from observational and document data, and they served 'to hold up a mirror' to help the design team reflect on their ongoing work and identify critical issues to be addressed. Meetings were convened on two occasions with the design team to share the interim findings. Based on the study's theoretical framework, the 'mirror holding' meetings presented information about designer thinking behind the intended outcomes of student learning; the envisioned enactment of activities in the in-class curriculum and fieldwork to attain those outcomes; the written curriculum materials to achieve the vision and outcomes; and the design process followed to (re)shape these representations. In explicating the design process, the findings described the specific measures taken, requirements generated, insights gathered, and initial ideas proposed by the designers to support student learning. These meetings also served as member checks (Guba 1981) with designers to confirm and refine the reports as needed. The first report was discussed in May 2015, as schools were implementing materials for in-class and fieldwork activities. The second report was discussed in August 2015 as the team proceeded with initial redesign following the first implementation.

A short interview (Yin 2014) of approximately 90 minutes was conducted with the project leader in June 2015 to better understand the design work that had occurred prior to gathering observational data, and to clarify other data emerging from observations and documentation. Whereas a set of questions about designer thinking and processes behind specific project materials guided the interview, a conversational tone was maintained to facilitate discussion of designer thinking. Sample questions were: What were key design considerations in condensing the (original) 3-week curriculum into a 1-week curriculum? What was the motivation for creating 'Species Briefs' materials, and how did you envision its use? What specific feedback did you get from teachers during the professional development workshop in fall of 2014 ?

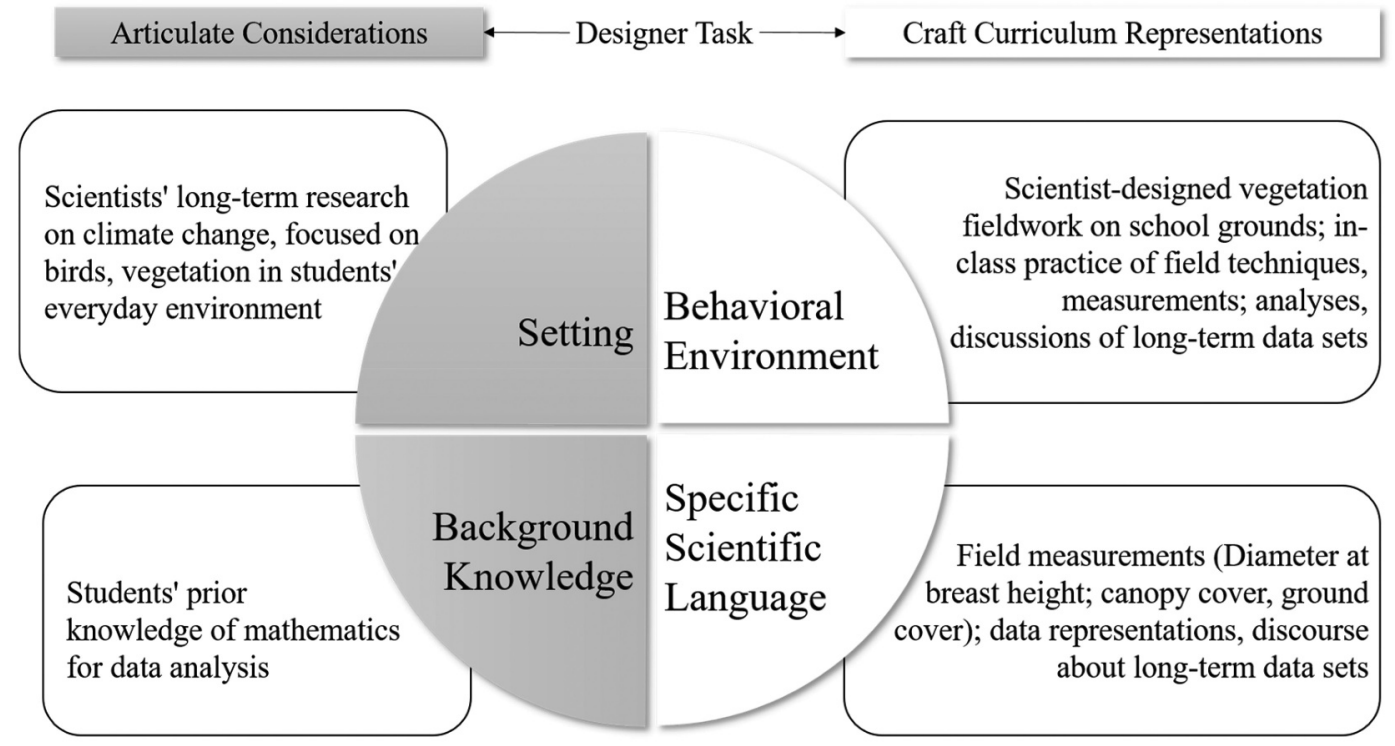

Figure 3. Manifestations of context attributes for scientific practices. 
Further, prolonged interviews (Yin 2014) were conducted with designers in January 2016; each lasted approximately two hours and was carried out individually with the designers in a single sitting. The aim of the interviews was to inquire into designer rationales, processes, and insights shaping each curriculum representation and the overall theory of action. To facilitate the interviews, designers were provided with an updated version of the researchers' interpretation of their evolving theory of action, articulating the curriculum representations developed to date. This information was prepared based on emerging interpretations of observational and document data. The interviews also helped verify the designers' theory of action and revise it as needed.

Based on the theoretical framework of the study presented earlier, a semi-structured protocol was created to guide the interviews. A sample question about the intended outcomes of students' learning were: Why were these goals for students' learning chosen by your team? Designers were also asked about their vision for enactment, for example: How did the team decide these [instructional] activities were important to support students' learning in this project? Finally, a sample question about their design rationales and processes for the written curriculum was: What sources of information guided your choices, for example, feedback from teachers, literature review, or observations made by the team?

\section{Data analysis}

The analyses were conducted according to the three snapshots of the curriculum design work to uncover how designer processes and curriculum representations evolved in response to specific needs and challenges. The data were analysed in two stages. First, during the 17-month period, fieldnotes of observations and document data were analysed based on the theoretical framework and research question (Miles and Huberman 1994) to examine designer processes and rationales behind the curriculum representations described previously. This step helped the researcher prepare interim analysis reports of the designers' evolving theory of action. The drafts were prepared by the first author and discussed with the co-authors until 100\% consensus was achieved. The drafts were revised again after member checks with the designers. Additionally, the interview transcripts were analysed by the first author to extract details about designer processes and rationales associated with specific curriculum representations. These interpretations were reviewed independently by the second author to confirm and extend the findings.

Second, following the 17-month period, the entire data set was reviewed to develop a comprehensive set of findings for a draft of a full case study report, with the multiple data sources serving to verify and elaborate the findings. This draft was discussed with the co-authors until 100\% consensus was attained. Table 1 describes the coding scheme used to analyse designer work. Finally, the findings were clarified and corroborated through member check with the curriculum project leader (Yin 2014).

\section{Results}

The data analysis revealed three intended outcomes of students' learning, which are used to organise the results section: students' understanding of key scientific practices; of climate science concepts; and of the value of local citizen-science action. Each sub-section begins with a paragraph describing the intended outcome and relevant designer work that occurred prior to gathering participant-observational data for this study, followed by work observed as part of the research study (Snapshots 1, 2 and 3). Each sub-section also includes a figure depicting how the four attributes of context-based learning (setting, background knowledge, behavioural environment, specific scientific language) manifest in specific designer tasks related to each outcome. Thereafter, each sub-section presents findings synthesised from multiple data sources (as indicated in Tables 2, 3 , and 4) that describe how designers shaped their processes and decisions to contribute to their evolving theory of action over time. Each snapshot reports envisioned enactment and/or written 


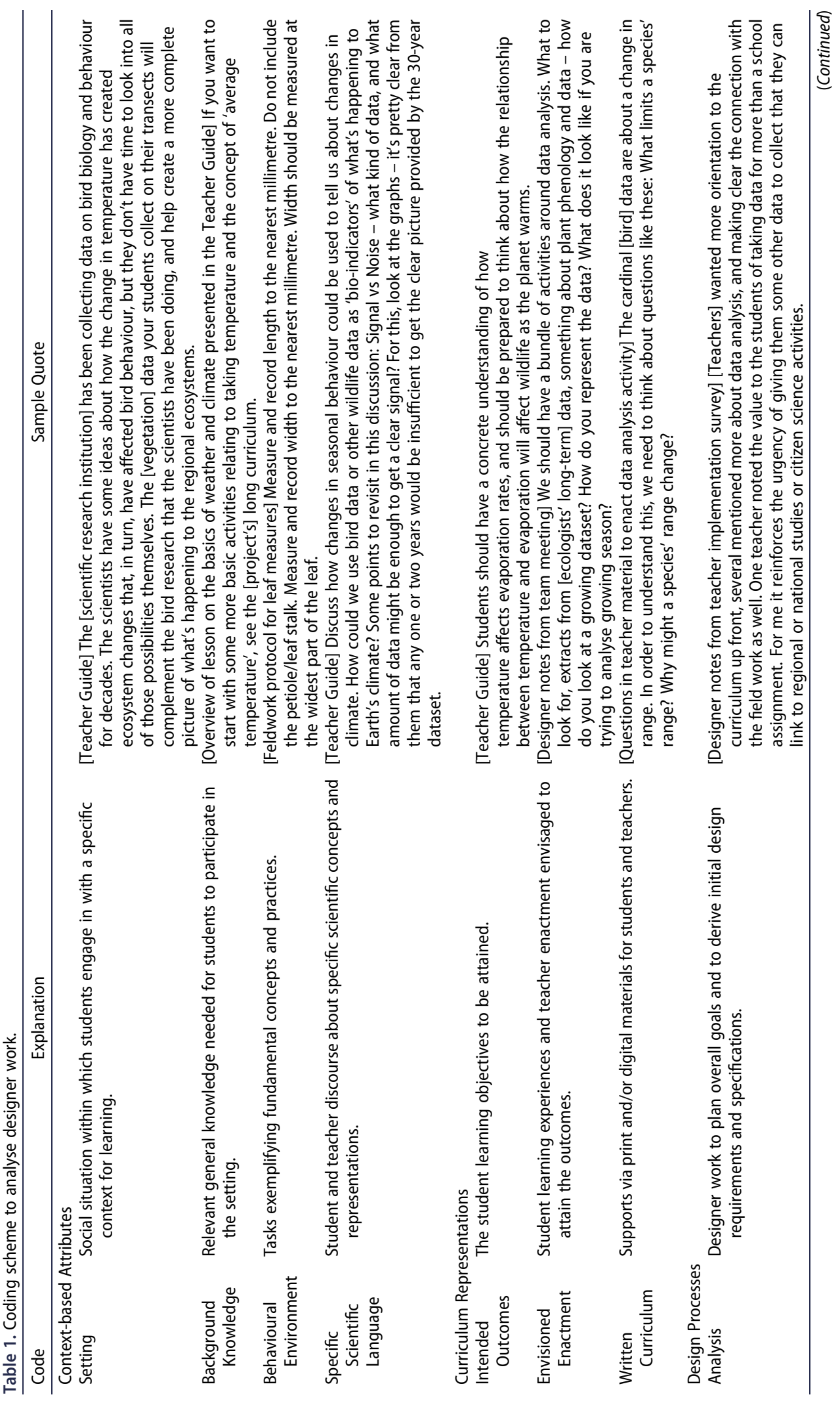




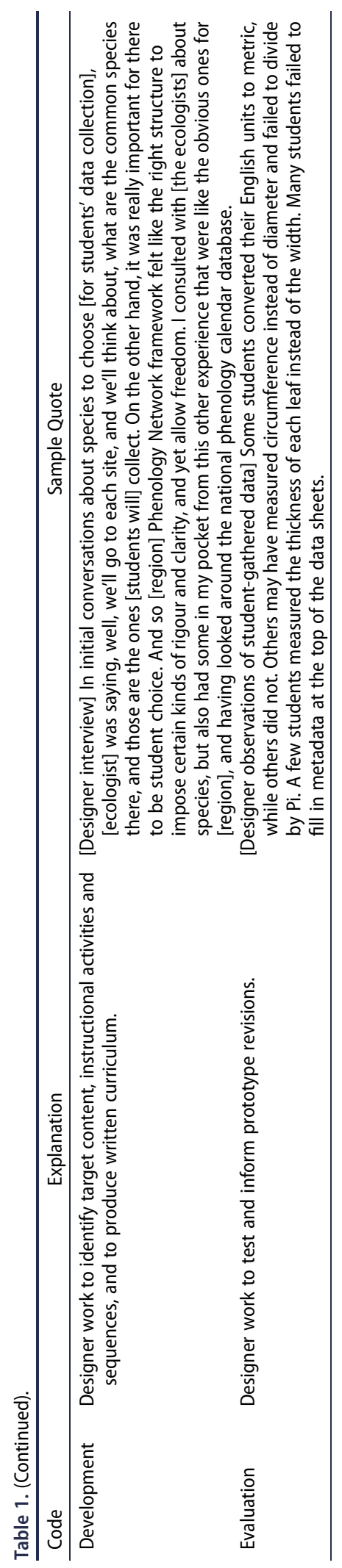


curriculum for the intended outcome and designer processes and rationales behind those representations.

\section{Intended outcome 1: scientific practices}

Designers aimed for students to understand scientific practices, such as using specific field techniques for measurement, generating hypotheses, analysing data and distinguishing signal from noise in longitudinal data sets. The target practices were related to the scientist-designed, standardised vegetation fieldwork component with which the in-class curriculum was meant to align (see Figure 3). In fall of 2014, external advisers had recommended tightly aligning the standardised field work with the in-class curriculum. Therefore, designers emphasised signal vs. noise detection in longterm data sets to help students understand how collecting long-term data could yield clear trends that would not be evident in short-term data. During this time, teachers expressed interest in integrating science with mathematics via data analysis activities, and stressed simple descriptive statistics, data quality, and data sets.

\section{Snapshot 1}

Student, teacher, and scientist interactions all take place within the setting of the latter's long-term research on bird movements and climate change. Designers imagined scientists would personally assist teachers and students to collect specific long-term standardised vegetation data on leaf length and width (to study leaf-out), canopy cover, and tree height and diameter at breast height (DBH).

As part of the behavioural environment, in-class curriculum activities were aligned with the scientists' research questions. To sharpen this alignment, following expert appraisal, the in-class curriculum was shortened from a 3-week to a 1-week sequence of lessons situating the fieldwork within foundational climate science theory, and it was organised around the central theme of signal vs. noise. The student materials and teacher guide included stepwise instructions to practise field measurements and techniques prior to fieldwork. The written curriculum also contained protocols and record sheets with stepwise procedures and hands-on kits (containing micrometres and DBH measuring tape) to enact the standardised fieldwork.

With respect to specific scientific language, the ecologists emphasised certain vegetation measurements and techniques because of the connection between vegetation and birds (vegetation as indirect indicator of insect availability) and because vegetation measurements were easier to implement with schools than bird measurements. The main considerations of the designers were to incorporate easily implementable techniques (e.g., using measuring tape to record leaf length and width); accessible and relevant measurements related to easily identifiable and abundant vegetation; reasonable sample size of vegetation data; and potential to generate clear meanings and long-term results from the fieldwork.

\section{Snapshot 2}

The designers' envisioned enactment shifted as they considered providing additional material supports for conducting standardised fieldwork, while reducing in-person assistance from scientists. This shift was critical to their overall endeavour of designing a scalable school-scientist partnership model. Further, their vision of the behavioural environment expanded to include supplementary in-class activities for analyses of authentic data sets, for which designers considered both the standardised vegetation data and other existing long-term data sets. As an ecologist elaborated during an interview, they wanted students to 'have at least some sort of exposure to field techniques to demystify science,' to make science 'more accessible', and to help students realise that 'anyone can contribute to this database.' 
This vision was influenced by designers' evaluation work. Previously in spring of 2015, they had observed the standardised fieldwork, noting the extent of teacher preparation, student engagement and understanding, and logistical challenges in data collection. Teachers and students were found to have insufficient understanding of fieldwork techniques. Teacher survey results confirmed the educational value of the fieldwork, while revealing that teachers needed more support to enact field techniques and data analysis activities. There were also difficulties with taking particular measurements, such as $\mathrm{DBH}$ and tree height. In a document describing observations of studentgathered data, an ecologist noted that the process was 'less-than-precise and open to enormous amounts of individual variation.' Additionally, the ecologists noted lack of metadata, failure to convert units of measurement, and incorrect measurements and calculations in student-gathered vegetation data.

To develop the written curriculum, designers began planning supplementary data analysis activities. Key considerations were students' prior knowledge of mathematics and state standards for mathematics content in target grades. Designers also emphasised data sets that were concrete, presented some variability, and had the potential to show obvious patterns, thus yielding clear answers and making data analyses rewarding to students. During team meetings, designers reasoned that to motivate teachers to enact data analytic activities, the measurements needed to show changes directly related to climate change, for example, leaf growth as opposed to tree height. Furthermore, to help students and teachers see how the data analytic activities fit with the curriculum and fieldwork, it was important to show conceptual links to foundational climate science theory. During interviews, a curriculum writer explained that integrating math into science, especially anything that has to do with environmental science, is a real challenge. One of the typical issues is that you get teachers to collect data and they don't want to do the analysis.' Providing teachers with access to authentic, longitudinal data sets was considered as a key benefit of partnering with scientists. However, as the curriculum writer clarified, 'scientific data sets are incomprehensible outside of the research project most of the time. So, there has to be an intermediary process.'

To that end, the ecologists proposed ideas for analysing longitudinal bird data from their own research and vegetation data from the standardised fieldwork. They visited school grounds to gather vegetation data to compare to student-gathered data and to select a subset of the data for inclusion in the curriculum.

Table 2. Data sources of key findings about scientific practices.

\begin{tabular}{|c|c|c|c|c|}
\hline Designer work & Key findings & $\begin{array}{l}\text { Designer } \\
\text { Interviews }\end{array}$ & $\begin{array}{l}\text { Designer } \\
\text { Team } \\
\text { Meetings }\end{array}$ & $\begin{array}{c}\text { Design } \\
\text { Documents }^{2}\end{array}$ \\
\hline \multirow{2}{*}{$\begin{array}{l}\text { Envisioned } \\
\text { Enactment }\end{array}$} & Standardised vegetation fieldwork (snapshot 1) & $\mathrm{x}$ & $x$ & $\mathrm{x}$ \\
\hline & $\begin{array}{l}\text { In-class supplementary data analyses, discussions } \\
\text { (snapshot 2) }\end{array}$ & $\mathrm{x}$ & $x$ & $x$ \\
\hline \multirow[t]{2}{*}{ Written Curriculum } & $\begin{array}{l}\text { Protocols, data record sheets, written and video tutorials for } \\
\text { standardised fieldwork (snapshots } 1,3 \text { ). }\end{array}$ & $\mathrm{x}$ & $\mathrm{x}$ & $\mathrm{x}$ \\
\hline & $\begin{array}{l}\text { Background information, stepwise procedures, questions for } \\
\text { data analyses (snapshot 3) }\end{array}$ & & & $\mathrm{x}$ \\
\hline \multirow{6}{*}{$\begin{array}{l}\text { Designer } \\
\text { Considerations } \\
\text { and Processes }\end{array}$} & $\begin{array}{l}\text { Easy techniques, accessible measurements, reasonable } \\
\text { sample size for standardised fieldwork (snapshot 1) }\end{array}$ & $\mathrm{x}$ & & \\
\hline & $\begin{array}{l}\text { Concrete measurements having variability, clear links to } \\
\text { climate change and theory for data analysis (snapshot 2) }\end{array}$ & & $\mathrm{x}$ & $\mathrm{x}$ \\
\hline & $\begin{array}{l}\text { Observations of fieldwork, student-gathered data, teacher } \\
\text { surveys revealed fieldwork challenges (snapshot 2) }\end{array}$ & $\mathrm{x}$ & $\mathrm{x}$ & $\mathrm{x}$ \\
\hline & $\begin{array}{l}\text { Students' prior knowledge, state mathematics standards } \\
\text { considered for data analyses (snapshot } 2 \text { ) }\end{array}$ & $\mathrm{x}$ & $\mathrm{x}$ & $\mathrm{x}$ \\
\hline & $\begin{array}{l}\text { Input gathered from teacher survey on available technology } \\
\text { for fieldwork (snapshot } 3 \text { ) }\end{array}$ & & $\mathrm{x}$ & $\mathrm{x}$ \\
\hline & $\begin{array}{l}\text { Vegetation and bird data gathered from ecologists for data } \\
\text { analytic activities (snapshot } 3 \text { ) }\end{array}$ & $\mathrm{x}$ & $\mathrm{x}$ & $\mathrm{x}$ \\
\hline
\end{tabular}




\section{Snapshot 3}

To develop teacher guides for in-class data analysis activities as part of the behavioural environment, the ecologists identified suitable variables from their data sets. Guided by considerations about background knowledge, the curriculum writers selected a small set of variables from those and structured the complex data sets to suit target students' data analytic skills and mathematics learning standards. They included background information on relevant species and key concepts, research hypotheses, stepwise procedures, and questions to prepare, analyse, interpret, and discuss long-term data sets. The written curriculum thus reinforced specific language via data representations and supports for scientific discourse. These supports were crucial because scientific data sets pose challenges in sense-making for non-scientists. Therefore, the data sets needed to be problematised and simplified to foreground key ideas.

Based on errors and limitations in student-gathered vegetation data from the standardised fieldwork, the ecologists revised fieldwork protocols to embed links to video tutorials illustrating specific techniques (e.g., using measuring devices to record leaf length and width to the nearest millimetre). Additionally, they revised data sheets to reinforce accurate data collection (e.g., leaf length/width data sheets now included details like plant species, latitude and longitude). Based on a survey to assess teacher access to different technologies, the ecologists also prepared a written tutorial for using basic GPS-based devices to aid standardised fieldwork.

Table 2 summarises key findings about scientific practices and indicates the data sources from which those findings were synthesised.

\section{Intended outcome 2: conceptual understanding}

Designers stressed student comprehension of key climate science concepts, such as weather and temperature. They also emphasised understanding the impact of climate change and the links between local and global climate change (see Figure 4). In fall of 2014, teachers had expressed the need for grade-appropriate readings to integrate science and literacy. They stressed shortening the original 3-week curriculum because it spanned content across grade levels. Furthermore, external advisers recommended deeper treatment of key scientific concepts, improved teacher access to content, and a condensed curriculum to address constraints on teachers' time.

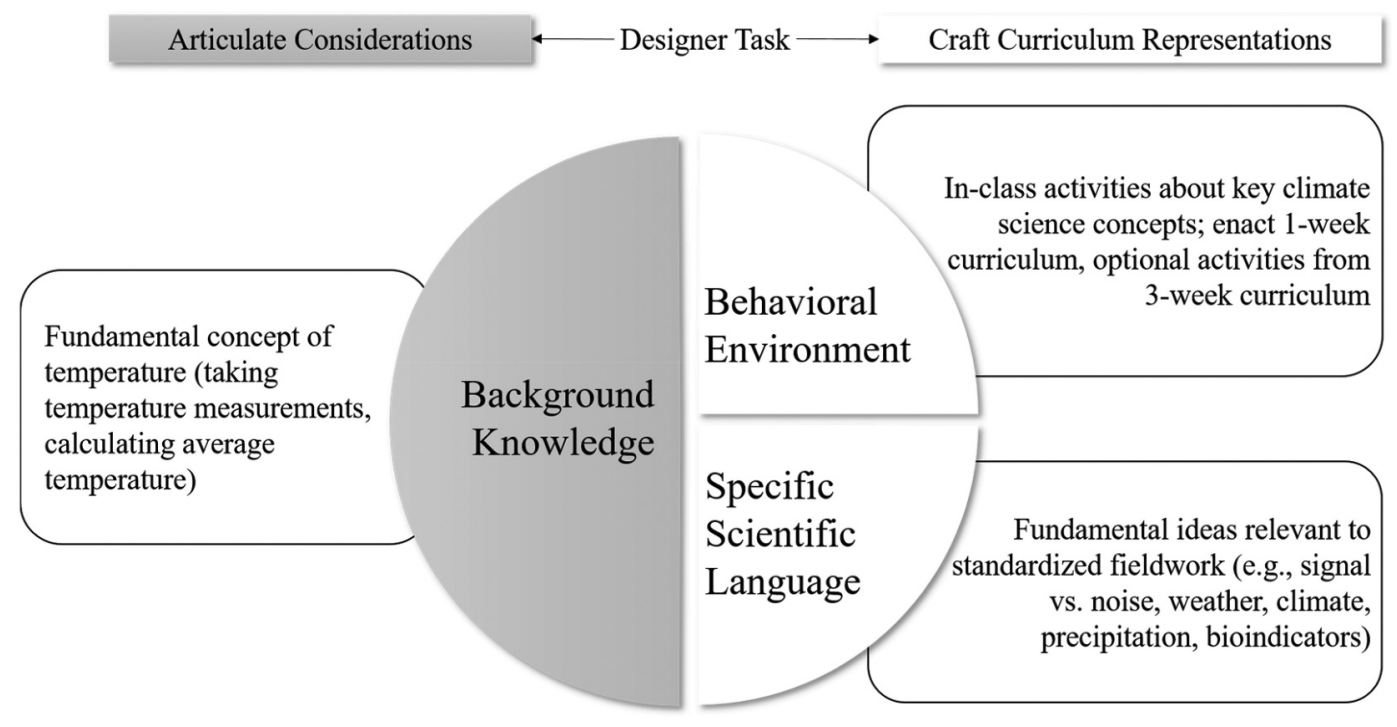

Figure 4. Manifestations of context attributes for conceptual understanding. 


\section{Snapshot 1}

For the behavioural environment, designers envisioned a range of in-class activities to introduce specific language related to key climate science concepts for motivating the standardised fieldwork. As explained during interviews, their vision included providing non-fiction science readings for background content to guide optional student inquiry into particular species.

Following expert appraisal, the written curriculum was condensed to a 1-week version highlighting specific organismal responses of local species and some global examples. For the behavioural environment, the student materials provided context for lessons and stepwise questions and prompts. The teacher guide clarified target concepts and connections to activities and lessons, and it also contained: stepwise prompts, questions and intended student responses, definitions of key terms (i.e., climate vs weather), and provided optional questions for lesson review, extension activities, and background readings. Finally, short non-fiction science reading resources called 'Species Briefs' were provided separately to enrich student learning. The readings described the 'range' of habitats of local organisms, life histories and responses to climate change.

To develop the 1-week curriculum, the curriculum writers attended to the specific scientific language, focusing on concepts that were not addressed in other subject areas, were typically challenging to enact, were related to longitudinal data collection, and were essential to contextualise the standardised fieldwork. Examples of local phenomena and species were included to motivate student learning about climate science as it related to their everyday lives. During an interview, as a curriculum writer explained their choices for the 1-week curricular content,

The conceptual framework behind the science was more important. But math, the geographical aspects, those are skills that one can learn in other contexts and then apply. But learning the concepts of signal vs. noise, the history of climate science, and what goes into figuring out how to do research, and how to get meaning from the data, that stuff is more important, both in terms of training scientists and in terms of training nonscientists who can come to terms with science in their everyday lives.

To create 'Species Briefs', the curriculum writers drew on species descriptions and a framework of organismal responses developed in a prior project, using species whose climate responses had been reported in the scientific literature. They also considered target students' reading level to identify accessible content.

\section{Snapshot 2}

The envisioned enactment of the behavioural environment evolved to emphasise teaching the 1-week curriculum because it was foundational for the standardised fieldwork. Designers also imagined including topics from the 3-week curriculum as optional modules based on students' background knowledge. This vision was shaped by the evaluation phase. Designers had observed that the 1-week curriculum had not been taught prior to the standardised fieldwork, and as an ecologist noted in a document, consequently, students and teachers had 'little idea as to why [they] were in the field.' A teacher survey indicated spotty enactment of the 1-week curriculum due to time constraints and a need for adaptations based on students' background knowledge. Teachers also expressed interest in enacting some activities from the 3-week curriculum. The written curriculum, however, was not immediately redesigned.

\section{Snapshot 3}

The vision for in-class activities of the behavioural environment continued to be refined. Designers imagined teachers would help students develop firm understandings of key concepts via observations and evidence, and guide students to conduct research on life histories of specific organisms. They also considered adapting the 1-week curriculum according to students' learning needs and class time constraints. 
Table 3. Data sources of key findings about conceptual understanding.

\begin{tabular}{|c|c|c|c|c|}
\hline Designer work & Key findings & $\begin{array}{l}\text { Designer } \\
\text { Interviews }\end{array}$ & $\begin{array}{l}\text { Designer } \\
\text { Team } \\
\text { Meetings }\end{array}$ & $\begin{array}{l}\text { Design } \\
\text { Documents }^{3}\end{array}$ \\
\hline Envisioned & Guide optional student inquiry (snapshot 1) & $x$ & & \\
\hline \multirow[t]{2}{*}{ Enactment } & $\begin{array}{l}\text { Teach 1-week unit as foundation before standardised } \\
\text { fieldwork (snapshot 2) }\end{array}$ & $\mathrm{x}$ & $\mathrm{x}$ & \\
\hline & $\begin{array}{l}\text { Teach optional 3-week unit as appropriate to student needs, } \\
\text { interests (snapshot 2) }\end{array}$ & & $\mathrm{x}$ & \\
\hline \multirow[t]{4}{*}{ Written Curriculum } & $\begin{array}{l}\text { Lesson context, stepwise questions, prompts in student } \\
\text { materials (snapshot 1) }\end{array}$ & & & $x$ \\
\hline & $\begin{array}{l}\text { Definitions, understanding goals, intended student } \\
\text { responses, stepwise questions in teacher materials } \\
\text { (snapshot 1,3) }\end{array}$ & & $\mathrm{x}$ & $\mathrm{x}$ \\
\hline & $\begin{array}{l}\text { Educative teacher notes to explain, exemplify, address } \\
\text { student thinking (snapshot } 3 \text { ) }\end{array}$ & & & $\mathrm{x}$ \\
\hline & Optional short species briefs (snapshot 1) & $x$ & & $x$ \\
\hline \multirow{6}{*}{$\begin{array}{l}\text { Designer } \\
\text { Considerations } \\
\text { and Processes }\end{array}$} & Selected content essential to situate fieldwork (snapshot 1) & $\mathrm{x}$ & & \\
\hline & Included local examples to motivate students (snapshot 1) & $x$ & & \\
\hline & Surveyed species frameworks from prior project (snapshot 1) & $x$ & & $x$ \\
\hline & $\begin{array}{l}\text { Observations revealed in-class unit not taught prior to } \\
\text { fieldwork (snapshot 2) }\end{array}$ & $x$ & $\mathrm{x}$ & $x$ \\
\hline & $\begin{array}{l}\text { Teacher survey revealed need for in-class unit adaptation } \\
\text { (snapshot 2) }\end{array}$ & & & $\mathrm{x}$ \\
\hline & $\begin{array}{l}\text { Pre-post written assessments revealed student difficulties } \\
\text { with specific concepts (snapshot } 3 \text { ) }\end{array}$ & $\mathrm{x}$ & & $\mathrm{x}$ \\
\hline
\end{tabular}

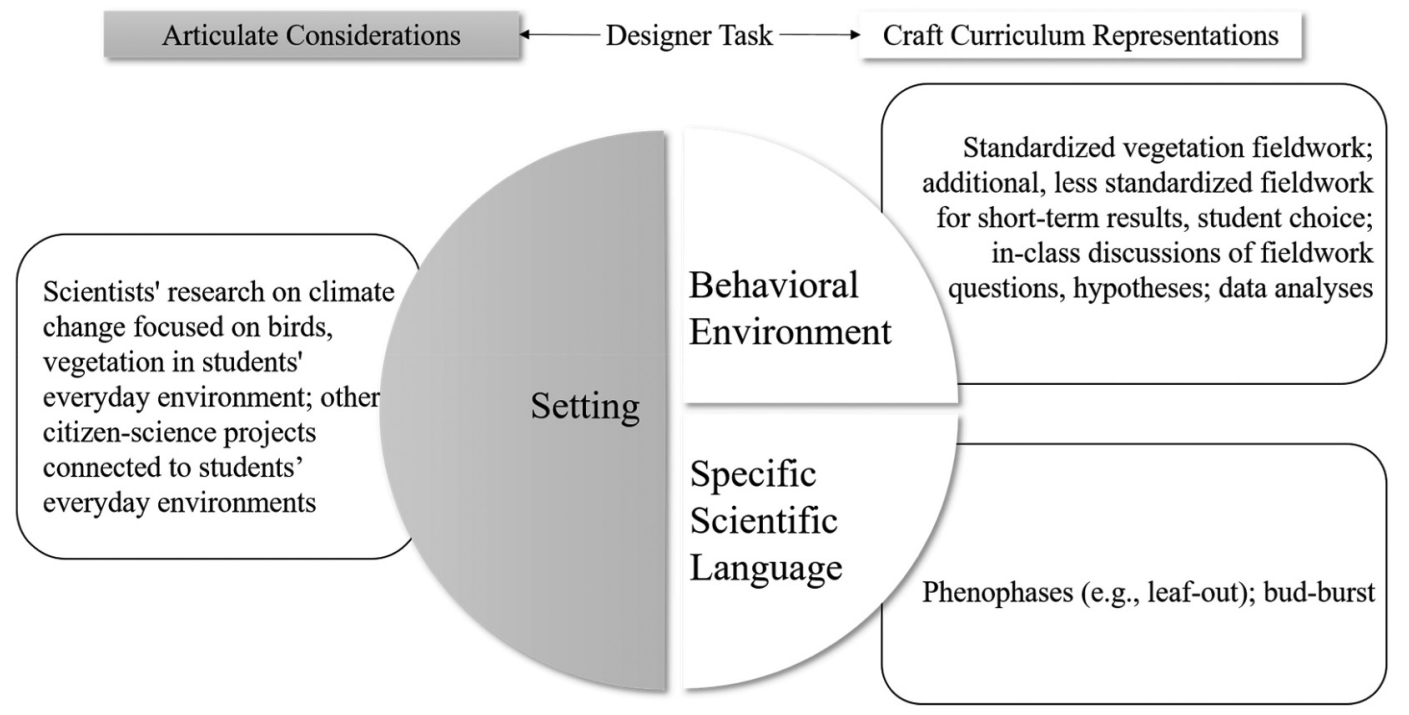

Figure 5. Manifestations of context attributes for valuing local action.

These refinements emerged from the evaluation phase. First, the curriculum writers analysed written pre-post assessments of student learning, noting the accuracy, completeness, relevance, and specificity in student responses. In so doing, they identified concepts, such as temperature and precipitation, that were difficult for students. Second, during a meeting with external advisers, it was recommended that the written materials specify the understanding goals of the science content for teachers. In response, the teacher guide for the 1-week curriculum included understanding goals of lesson activities, and pointers to activities from the 3-week curriculum on taking temperature and calculating average temperature to adapt to students' background knowledge. 
The written curriculum also included educative notes for teachers. The notes reinforced specific scientific language, explaining students' emergent or alternative understanding of challenging ecological concepts, such as distinctions between weather and climate, exemplified these with student responses from pre-post assessments, and offered strategies to address students' thinking. The curriculum writers honed the educative notes following feedback from the ecologists about including specific species examples and case studies to support in-class activities.

Table 3 summarises key findings about conceptual understanding and indicates the data sources from which those findings were synthesised.

\section{Intended outcome 3: valuing local action}

Designers aspired for students to understand how local citizen-science endeavours can contribute to broader scientific research on climate change (see Figure 5). In fall of 2014, external advisers had noted that the 3-week curriculum did not sufficiently motivate students for scientist-designed standardised fieldwork. They recommended explicating connections to the long-term research and fieldwork goals of the ecologists.

\section{Snapshot 1}

Following the appraisal from external advisers, designers envisioned connecting students' standardised vegetation fieldwork to the ecologists' long-term research on bird responses to climate change, as evidenced in the local surroundings. To do so, with respect to the behavioural environment, they imagined whole-class discussions about questions and hypotheses behind the research. With input from the ecologists, the curriculum writers included in the 1-week curriculum the rationale and hypotheses of the fieldwork to explain how it contributed to the scientists' current research on birds, i.e., the setting. This information aimed to help both teachers and students understand how the inclass activities and fieldwork were in the service of the scientists' research program. Whereas vegetation measurements may have low appeal for secondary school students, designers hoped that the ultimate connection to local bird research would motivate students. As a curriculum writer recalled during the interviews,

\footnotetext{
The [standardized] data collection that the students are doing is actually related to [the scientific research institution's] hypotheses and research questions. And it took me a while to realize that it was actually really important to foreground those. And I have a little confirmation of this, because when I handed [the curriculum material about articulating the research program] to [partner teachers], they were really grateful because it was a missing ingredient. And then their response was, the thing that gets these [students] really excited is we're really doing this for real scientists.
}

\section{Snapshot 2}

The vision to connect students' fieldwork with the setting of ongoing scientific research expanded as designers considered additional, supplementary citizen-science activities. These activities were crucial to promote student ownership over data collection, yield short-term results with clearer contributions to authentic, growing data sets, and thereby provide more rewarding experiences with data. Designers envisaged students would formulate research questions, gather data, compare data sets from other participating schools, and contribute local data to broad citizen-science movements.

This expanded vision stemmed from designers' evaluation work. A prospective teacher participant stressed greater student choice in fieldwork activities. Moreover, designers wrestled with the standardised, long-term vegetation data because some measurements, such as tree height did not yield 'immediate' results in terms of climate change, and they did not present enough variability to help students learn about the natural world. Limitations and errors in student-gathered vegetation 
data noted previously also influenced designers' decision to emphasise additional channels for collecting less standardised data, thus improving the chances of contributing the data to scientific research endeavours. Finally, during team meetings, designers reasoned that connecting students' fieldwork clearly with specific scientific research programmes would augment its authenticity.

Therefore, the curriculum contained a teacher guide for an optional 'Phenology Calendar' activity. For specific scientific language, the teacher guide provided background information and briefs on phenology observations. It presented the rationale behind collecting phenology data, criteria for collecting data on phenophases from different taxa - birds, plants, insects - and guidelines for reporting findings. With respect to the behavioural environment, there were guidelines for in-class data analyses and extension activities.

To develop these materials, the team drew inspiration from existing citizen-science phenology programs. The curriculum writers referred to a regional phenology network framework to select useful indicator species, derive phenological indicators to observe, and suggest a structure for the activity. In addition to providing student choice, they emphasised data common to all participating schools to help students learn from variability in school sites. Accordingly, after surveying vegetation and birds near the school sites, the ecologists selected species and indicators that were easily accessible and recognisable to students, had easily observable phenophases, and were practical to measure, such as first frog calls, leaf-out, and flowering. They stressed presence/absence measures, rather than those requiring precise measures of quantity. See the following interview quote from an ecologist about the considerations behind choosing species and indicators:

\footnotetext{
We had to choose birds that are really obvious. Can you see a robin coming back after spring migration? Can you find red-winged blackbirds? These are birds that anyone can recognize. Three of the schools we are dealing with now have ospreys very close by in the areas where they are measuring plants. So the students and teachers can be familiar with ospreys. We had to choose simple birds, simple plants, simple indicators. Is there a yellow dandelion flower? Probably the first time a student sees a dandelion, it might be in their backyard. But that's okay. What [students] are doing is, they are learning the technique of, when do things first emerge, and putting it into the context of, is this happening earlier? Is it due to climate change? We had to really adapt the species to the school year, the curriculum, the [seasonal] timing that we had, and what was practical in terms of getting students measuring.
}

\section{Snapshot 3}

With respect to the setting, designers continued to ponder citizen-science opportunities to help students contribute data to scientific research projects with a clearly articulated research agenda. This additional fieldwork was critical to make climate science more accessible to students and to develop their awareness of how non-scientists can contribute to it. The refined vision emerged from designers' development work. They noted challenges in using student-gathered standardised vegetation data for immediate scientific research on climate change. Whereas the standardised data collection 'demystified science', it was important to include measurements whose relevance to climate change was understandable to students.

The written curriculum now included supports for fieldwork in the service of a scientific research project on twigs cut from dormant woody plants. The project was being conducted at a local university to understand plant responses to climate change. For specific language, there were educative notes on science background information, significance of the scientific research project, and science briefs on relevant topics, such as leaf-out and bud-burst. To clarify and connect the fieldwork to the setting of the scientists' research, there were research questions and stepwise procedures for data identification, collection, monitoring and contribution. For the behavioural environment, the materials also supported in-class data analysis and comparisons across sites. The curriculum writers gathered input from scientists at the university to prepare these materials. 
Table 4. Data sources of key findings about valuing local action.

\begin{tabular}{|c|c|c|c|c|}
\hline Designer work & Key findings & $\begin{array}{c}\text { Designer } \\
\text { Interviews }\end{array}$ & $\begin{array}{l}\text { Designer } \\
\text { Team } \\
\text { Meetings }\end{array}$ & $\begin{array}{c}\text { Design } \\
\text { Documents }^{4}\end{array}$ \\
\hline \multirow[t]{2}{*}{$\begin{array}{l}\text { Envisioned } \\
\text { Enactment }\end{array}$} & $\begin{array}{l}\text { Class discussions to connect standardised fieldwork to } \\
\text { scientists' long-term research (snapshot 1) }\end{array}$ & & & $x$ \\
\hline & $\begin{array}{l}\text { Optional data collection to promote student choice, short-term } \\
\text { results, contribution to authentic research (snapshots } 2,3 \text { ) }\end{array}$ & $x$ & $x$ & \\
\hline \multirow[t]{4}{*}{ Written Curriculum } & $\begin{array}{l}\text { Standardised fieldwork rationale, hypotheses clarified in } \\
\text { 1-week curriculum (snapshot 1) }\end{array}$ & $\mathrm{x}$ & & $x$ \\
\hline & $\begin{array}{l}\text { Briefs, data collection criteria, stepwise guidelines for analysis, } \\
\text { reporting in teacher guide for phenology calendar activity } \\
\text { (snapshot 2) }\end{array}$ & & & $x$ \\
\hline & $\begin{array}{l}\text { Educative notes on science briefs, research significance, } \\
\text { stepwise procedures for data collection, analysis, } \\
\text { contribution for university project (snapshot 3) }\end{array}$ & & & $x$ \\
\hline & $\begin{array}{l}\text { Tips, protocols for 'packages' of fieldwork, in-class activities } \\
\text { (snapshot 3) }\end{array}$ & & & $x$ \\
\hline \multirow{6}{*}{$\begin{array}{l}\text { Designer } \\
\text { Considerations } \\
\text { and Processes }\end{array}$} & $\begin{array}{l}\text { External appraisal stressed stronger motivation for } \\
\text { standardised fieldwork (snapshot 1) }\end{array}$ & $\mathrm{x}$ & $x$ & $x$ \\
\hline & $\begin{array}{l}\text { Teacher feedback stressed greater student choice in fieldwork } \\
\text { (snapshot 2) }\end{array}$ & & $x$ & \\
\hline & $\begin{array}{l}\text { Limitations in student-gathered data implied need for less } \\
\text { standardised data (snapshot 2) }\end{array}$ & & $x$ & \\
\hline & $\begin{array}{l}\text { Citizen-science examples, regional phenology network } \\
\text { surveyed for indicators (snapshot 2) }\end{array}$ & $\mathrm{x}$ & $x$ & \\
\hline & $\begin{array}{l}\text { Vegetation, birds near school sites surveyed to identify } \\
\text { potential species for phenology calendar activity } \\
\text { (snapshot 2) }\end{array}$ & $x$ & $x$ & \\
\hline & $\begin{array}{l}\text { Focus on easily recognisable, observable, measurable species, } \\
\text { indicators for phenology calendar activity (snapshot 2) }\end{array}$ & $\mathrm{x}$ & $x$ & \\
\hline
\end{tabular}

Towards the end of this period, to reinforce an array of learning activities and connections therein, curriculum writers also began highlighting a 'package' metaphor consisting of a collection of in-class and fieldwork activities. To manifest this metaphor in the written curriculum, a menu of options was created. The menu presented packages of scientific research question, data collection techniques (including the standardised vegetation data), and related in-class curriculum activities. It offered tips for field activities and protocols contributing to different scientific research programmes on climate change. Finally, it identified key science concepts behind each activity and relevant science and mathematics learning standards and in-class activities. The menu was developed after the researchers had finished collecting data for the present case study. Hence, the paper does not report the design process behind this material.

Table 4 summarises the key findings about valuing local action and indicates the data sources from which those were synthesised.

\section{Discussion}

This participant-observation case study sought to generate a detailed worked example of designer thinking and processes in tackling emergent challenges while creating a school-based citizenscience curriculum. To do so, the study answered the following question: In designing schoolbased citizen-science curriculum, how do designers shape the processes and decisions that contribute to their evolving theory of action over time? The main findings are summarised in Tables 2,3 , and 4 , and the key insights from these findings are elaborated below. 


\section{Reflections and implications for educational design}

A holistic reflection on the findings reveals four key considerations of designers that contributed to their evolving theory of action for supporting school-based citizen-science. This section describes each consideration in light of existing literature and presents implications to aid those designers wishing to pursue similar endeavours.

\section{Creating the learning environment around the fieldwork}

The initial model of citizen-science embodied in this curriculum was of the contributory type (Bonney et al. 2009), involving scientist-designed research goals and protocols based on their prior work. Designers wanted students to primarily collect and contribute specific long-term, standardised vegetation data towards the research goals of the ecologists in studying migratory bird responses to climate change. But the connection between local vegetation data and bird data was initially not clear to teachers or students, nor was the rationale of collecting long-term data in studying climatic phenomena. Hence, designers revised the in-class curriculum to situate fieldwork within foundational climate science theory and aligned in-class activities with the scientists' research goals. Making these points explicit is crucial for students' engagement with the context of the curriculum, and to help them appreciate how the science they learn is relevant to their lives and to society more broadly (see Gilbert, 2006).

Another crucial need was to support students in analysing data sets. Here too, designers considered sense-making difficulties in engaging with authentic scientific data sets. By providing structures and stepwise guidelines in the written curriculum, the designers strove to make this scientific practice less complex while highlighting its core elements (Edelson and Reiser 2006). Data analysis is an important scientific practice emphasised in curriculum frameworks (NGSS Lead States 2013). Therefore, to help students and teachers engage with this practice, as instantiated in the present case, designers may select and curate data sets gathered from scientific research. To do so, they may administer surveys to inquire into teachers' needs for meeting curriculum standards (Doubler 1997; Edelson 2002) and draw on partner scientists' expertise (McKenney \& Reeves,2019).

\section{Tackling concerns about data quality and utility}

The designers of this curriculum noted limitations in student-gathered standardised data and insufficient teacher preparation to facilitate fieldwork. These issues made it difficult to use studentgathered data in contributing towards actual scientific research, which is a key goal of citizen-science endeavours. Indeed, the concerns with data quality and utility are common in implementing citizenscience projects (Houseal, Abd-El-Khalick, and Destefano 2014; Jordan et al. 2012). To respond to this problem, designers refined the instructional activities. Specifically, designers supplemented the fieldwork protocols with video and written tutorials and revised the data sheets to clarify fieldwork techniques and reinforce accurate data collection. Therefore, to help students contribute rigorous data towards scientific research, as exemplified in this work, designers may attend carefully during formative evaluation of the curriculum implementation (Gustafson and Branch 2002), observing teacher facilitation, student engagement, and the quality of student-gathered data.

\section{Making scientist-designed fieldwork engaging to students}

Because the standardised vegetation fieldwork was initially not strongly motivated for students in this curriculum, designers modified the behavioural environment in two ways. First, they clarified in the 1-week curriculum the fieldwork's purposes and contributions to the long-term research on birds being conducted by the ecologists. The written materials supported in-class discussions about underlying questions and hypotheses. Second, designers refined their vision to emphasise teaching 
the 1-week curriculum prior to the fieldwork. These measures thus aimed to help students value and engage productively with the setting (related to a community of scientists), in which they were to investigate climate change and learn the underlying science (Gilbert, Bulte, and Pilot 2011). In fact, communicating clearly a scientific agenda and potential utility of the data is a chief consideration in designing citizen-science projects (Bonney and Dickinson 2012). To do so, as seen in this case study, designers may seek feedback from external advisers (Schwartz 2006).

\section{Balancing scientific and educational goals}

A pressing concern with scientist-designed fieldwork is that students have little ownership over the underlying scientific agenda; they have few opportunities to engage with key scientific practices that go beyond data collection. To resolve this issue, the designers of the present curriculum developed materials to support additional student investigations. These revisions provided greater fieldwork options, including more structured inquiry embodied in the standardised vegetation fieldwork and more open inquiry embodied in the 'Phenology Calendar' activity (Trautmann et al. 2012). They enabled greater student choice in formulating research questions and hypotheses, identifying suitable measurements, collecting and analysing data, and communicating the findings. These design decisions are consistent with prior work that emphasises student experience of the full scientific inquiry process to help them develop deep understanding of scientific concepts and practices (Doubler 1997). Studies have argued for helping students plan and conduct their own investigations related to authentic scientific research (Houseal, Abd-El-Khalick, and Destefano 2014; Trautmann et al. 2012). Hence, to support varied fieldwork opportunities, as demonstrated in this case, designers may draw on teacher feedback, their own observations of the fieldwork implementation, local expertise, and inspiring examples of other citizen-science programs and related networks (McKenney \& Reeves,2019).

\section{Study limitations and implications for educational research}

Whereas the participant-observation approach presented several affordances, there were also some limitations. These are elaborated below, along with methodological and theoretical implications.

First, the present findings have limited generalisability, as with all case studies. Therefore, further research needs to be conducted to develop a broader knowledge base of designer thinking and strategies for integrating formal curriculum with citizen-science fieldwork. Second, the study reported in this paper concluded before the designers conducted the final evaluation and redesign of the curriculum. As a result, these phases of the design work were absent in the present research. This also meant that information on the attainment of specific educational and scientific outcomes was not available during the study. Hence, the data analysis could not uncover the effectiveness of the designers' processes and decisions with respect to the different curriculum representations. Therefore, future studies could include such data to unpack how specific designer decisions influence student motivation and attitudes, teaching practices, and the utility of student-gathered data for scientific research.

Finally, the present analyses did not unpack the underlying partnership model involving students, teachers, and ecologists, and the role of the curriculum writers in 'mediating' this partnership. Specifically, future research could uncover how scientists and school partners can be supported to learn from one another, as they cross boundaries between the cultures of schools and scientific research. Prior work highlights various mechanisms by which learning occurs at the boundary, such as those of identification and reflection in which individuals come to understand the differences among institutional practices (Akkerman and Bakker 2011). How might designers create specific supports that embody these and other mechanisms? This is a fruitful direction for future work as scientist-educator partnerships gain prominence to support science education (Drayton and Falk 2006). 


\section{Final remarks}

This study uncovered the challenges encountered by designers of school-based citizen-science curricula aimed at supporting environmental education. The study also portrayed their responses to those challenges, which can be useful to others engaged in similar endeavours. As a modest but unique contribution in this direction, the present study reveals not only the different ways in which designers' ideas were represented in the curriculum, but also brings to the fore the meticulous thinking and measures behind the evolution of those ideas. Through its detailed description of designer considerations and processes that helped refine their theory of action, the study thus enables a vicarious experience of the present design that can help other designers derive insights to guide their own choices (Howard et al. 2012). Finally, the four considerations as noted from the designers' initial work highlight key issues to attend to in other projects involving school-based citizen-science for environmental education.

\section{Notes}

1. This research was approved by the Institutional Review Board at $\square$ research organisation $\square$ under protocol $\square \# \square[$ This research was approved by the Institutional Review Board at TERC].

2. The design documents for this intended outcome consisted of drafts of the written curriculum, designer emails, memos, planning documents, curriculum project grant proposal, and teacher surveys.

3. The design documents for this intended outcome consisted of drafts of the written curriculum, designer emails, memos, planning documents, annual progress reports to funding agency, teacher surveys, and written pre-post assessments of student learning.

4. The design documents for this intended outcome consisted of drafts of the written curriculum, and designer emails, memos, and planning documents.

\section{Acknowledgments}

This work was supported by the National Science Foundation under grants \# 1252416, 1251562, and 1252373. The opinions expressed are those of the authors and do not represent views of the funding agency. The authors thank Brian Drayton for his feedback as a critical friend throughout various stages of this research. The authors also thank the research participants.

\section{Data Availability}

The original data cannot be shared due to concerns related to confidentiality, as per the research organization's Institutional Review Board.

\section{Disclosure of potential conflicts of interest}

No potential conflict of interest was reported by the author(s).

\section{Funding}

This work was supported by the National Science Foundation [1252416, 1251562, 1252373].

\section{ORCID}

Anushree Bopardikar (iD http://orcid.org/0000-0003-0088-1613

Debra Bernstein (iD http://orcid.org/0000-0001-5388-4506

Susan McKenney (iD) http://orcid.org/0000-0002-6028-4098 


\section{References}

Akkerman, S. F., and A. Bakker. 2011. "Boundary Crossing and Boundary Objects." Review of Educational Research 81 (2): 132-169. doi:10.3102/0034654311404435.

Alkaher, I., and D. Gan. 2020. “The Role of School Partnerships in Promoting Education for Sustainability and Social Capital." The Journal of Environmental Education51(6) 1-18.

Author references blinded.

Barstow, D. (1997). The Richness of Two Cultures. In National Conference on Student \& Scientist Partnerships, $33-37$. Cambridge, MA: TERC and Concord Consortium.

Bennett, J., and J. Holman. 2002. "Context-based Approaches to the Teaching of Chemistry: What are They and What are Their Effects?.” In Chemical Education: Towards Research-based Practice, edited by J. K. Gilbert, O. De Jong, R. Justi, D. F. Treagust, and J. H. Van Driel, 165-184. Dordrecht, The Netherlands: Kluwer Academic Publishers.

Bismack, A. S., A. M. Arias, E. A. Davis, and A. S. Palincsar. 2015. "Examining Student Work for Evidence of Teacher Uptake of Educative Curriculum Materials.” Journal of Research in Science Teaching 52 (6): 816-846. doi:10.1002/ tea.21220.

Bonney, R., and J. L. Dickinson. 2012. “Overview of Citizen Science.” In Citizen Science: Public Participation in Environmental Research, edited by J. L. Dickinson and R. Bonney, 19-26. New York: Cornell University Press.

Bonney, R., H. Ballard, R. Jordan, E. McCallie, T. Phillips, J. Shirk, and C. C. Wilderman (2009). Public participation in scientific research: Defining the field and assessing its potential for informal science education. A CAISE inquiry group report. Washington, DC: Center for Advancement of Informal Science Education (CAISE).

Bonney, R., T. Phillips, H. L. Ballard, and J. W. Enck. 2015. "Can Citizen Science Enhance Public Understanding of Science?." Public Understanding of Science25(1) 1-15.

Cherif, A. H. 1992. "Barriers to Ecology Education in North American High Schools: Another Alternative Perspective.” The Journal of Environmental Education 23 (3): 36-46. doi:10.1080/00958964.1992.9942800.

Clarke, J., and C. Dede. 2009. "Design for Scalability : A Case Study of the River City Curriculum." Journal of Science Education and Technology 18 (4): 353-365. doi:10.1007/s10956-009-9156-4.

Davis, E. A., A. S. Palincsar, A. M. Arias, A. S. Bismack, A. M. Marulis, and S. K. Iwashyna. 2014. "Designing Educative Curriculum Materials: A Theoretically and Empirically Driven Process." Harvard Educational Review 84 (1): 24-53. doi:10.17763/haer.84.1.g48488u230616264.

Deveci, İ., and İ. Karteri. 2020. "Context-Based Learning Supported by Environmental Measurement Devices in Science Teacher Education: A Mixed Method Research.” Journal of Biological Education 1-26. doi:10.1080/ 00219266.2020.1821083.

Dickinson, J. L., and R. Bonney. 2012. "Introduction: Why Citizen Science. 1-14." In Citizen Science: Public Participation in Environmental Research, edited by J. L. Dickinson and R. Bonney, 1-14. Ithaca, New York: Cornell University Press.

Doubler, S. J. (1997). Two-way Partnerships: An Introduction to SSPs. In National Conference on Student $ひ S c i e n t i s t$ Partnerships, 23-26. Cambridge, MA: TERC and Concord Consortium.

Drayton, B., and J. Falk. 2006. "Dimensions that Shape Teacher-scientist Collaborations for Teacher Enhancement." Science Education 90 (4): 734-761. doi:10.1002/sce.20138.

Edelson, D. C. 2002. “Design Research: What We Learn When We Engage in Design.” Journal of the Learning Sciences 11 (1): 105-121. doi:10.1207/S15327809JLS1101_4.

Edelson, D. C., and B. J. Reiser. 2006. "Making Authentic Practices Accessible to Learners: Design Challenges and Strategies." In The Cambridge Handbook of the Learning Sciences, edited by R. K. Sawyer, 335-354. New York: Cambridge University Press.

Edelson, D. C., D. N. Gordin, and R. D. Pea. 1999. “Addressing the Challenges of Inquiry-based Learning through Technology and Curriculum Design.” Journal of the Learning Sciences 8 (3-4): 391-450.

Emerson, R. M., R. I. Fretz, and L. L. Shaw. 1995. Writing Ethnographic Fieldnotes. Chicago: University of Chicago Press.

Finkelstein, N. 2005. "Learning Physics in Context: A Study of Student Learning about Electricity and Magnetism.” International Journal of Science Education 27 (10): 1187-1209. doi:10.1080/09500690500069491

Foss, A. W., and Y. Ko. 2019. "Barriers and Opportunities for Climate Change Education: The Case of Dallas-Fort Worth in Texas.” The Journal of Environmental Education 50 (3): 145-159. doi:10.1080/00958964.2019.1604479.

Gilbert, J. K. (2006). “On the Nature of „Context“ in Chemical Education,.. International Journal of Science Education, 28(9), 957-976

Gilbert, J. K. 2006. “On the Nature of “Context” in Chemical Education.” International Journal of Science Education 28 (9): 957-976. doi:10.1080/09500690600702470.

Gilbert, J. K., A. M. W. Bulte, and A. Pilot. 2011. "Concept Development and Transfer in Context-based Science Education.” International Journal of Science Education 33 (6): 817-837. doi:10.1080/09500693.2010.493185.

Goodlad, J., M. Klein, and K. Tye. 1979. “The Domains of Curriculum and Their Study.” In Curriculum Inquiry: The Study of Curriculum Practice, edited by J. Goodlad, 43-76. Associates. New York: McGraw-Hill. 
Gray, S. A., K. Nicosia, and R. C. Jordan. 2012. "Lessons Learned from Citizen-science in the Classroom.” Democracy \& Education 20 (2): 1-5.

Guba, E. G. 1981. "Criteria for Assessing the Trustworthiness of Naturalistic Inquiries.” Educational Communication and Technology 29 (2): 75-91.

Gustafson, K. L., and R. Branch. 2002. Survey of Instructional Design Models. 4th ed. Syracuse University: ERIC Clearninghouse on Information Resources.

Harlin, J., L. Kloetzer, D. Patton, and C. Leonhard, Leysin American School high school students. 2018. “Turning Students into Citizen Scientists." In Citizen Science: Innovation in Open Science, Society and Policy, edited by S. Hecker, M. Haklay, A. Bowse, Z. Makuch, J. Vogel, and A. Bonn, 410-428. UCL Press: London.

Holmqvist Olander, M., and C. Olander. 2017. "Understandings of Climate Change Articulated by Swedish Secondary School Students.” Journal of Biological Education 51 (4): 349-357. doi:10.1080/00219266.2016.1233130.

Houseal, A. K., F. Abd-El-Khalick, and L. Destefano. 2014. "Impact of a Student-teacher-scientist Partnership on Students' and Teachers' Content Knowledge, Attitudes toward Science, and Pedagogical Practices." Journal of Research in Science Teaching 51 (1): 84-115. doi:10.1002/tea.21126.

Howard, C. D., E. Boling, G. Rowland, and K. M. Smith. 2012. "Instructional Design Cases and Why We Need Them." Educational Technology 52 (3): 34.

Jordan, R. C., J. G. Ehrenfeld, S. A. Gray, W. R. Brooks, D. V. Howe, and C. E. Hmelo-Silver. 2012. "Cognitive Considerations in the Development of Citizen Science Projects." In Citizen Science: Public Participation in Environmental Research, edited by J. L. Dickinson and R. Bonney, 167-178. Ithaca, NY, USA: Cornell University Press.

Kelemen-Finan, J., M. Scheuch, and S. Winter. 2018. "Contributions from Citizen Science to Science Education: An Examination of a Biodiversity Citizen Science project with Schools in Central Europe.” International Journal of Science Education 40 (17): 2078-2098. doi:10.1080/09500693.2018.1520405.

Kolodner, J. L., Camp, P. J., Crismond, D., Fasse, B., Gary, J., Holbrook, J., \& Ryan, M. (2003). "Problem-Based Learning Meets Case-Based Reasoning in the Middle School Science Classroom: Putting Learning By Design into practice., Journal of the Learning Sciences, 12(4), 495-547

Krajcik, J. S., K. L. McNeill, and B. J. Reiser. 2008. "Learning-goals-driven Design Model: Developing Curriculum Materials that Align with National Standards and Incorporate Project-based Pedagogy." Science Education 92 (1): 1-32. doi:10.1002/sce.20240.

Lawson, B. (2004). Schemata, gambits, and precedent: Some factors in design expertise. Design Studies, 25(5), 443457

McKenney, S., \& Reeves, T. C. (2019). Conducting educational design research(2nd Ed.). London: Routledge

McLaughlin, C. A., J. Broo, B. J. MacFadden, and S. Moran. 2016. "Not Looking a Gift Horse in the Mouth: Exploring the Merits of a Student-teacher-scientist Partnership." Journal of Biological Education 50 (2): $174-184$. doi:10.1080/00219266.2015.1028571.

McNeill, K. L., Lizotte, D. J., Krajcik, J. S., \& Marx, R. W. (2006). “Supporting Students' Construction of Scientific Explanations by Fading Scaffolds in Instructional Materials., ,Journal of the Learning Sciences, 15(2), 153-191

Merriam, S. B. 1988. Case Study Research in Education: A Qualitative Approach. San Francisco: Jossey-Bass.

Miles, M. B., and A. M. Huberman. 1994. Qualitative Data Analysis: An Expanded Sourcebook. Thousand Oaks, California: Sage.

Monroe, M. C., R. R. Plate, A. Oxarart, A. Bowers, and W. A. Chaves. 2019. "Identifying Effective Climate Change Education Strategies: A Systematic Review of the Research.” Environmental Education Research 25 (6): 791-812. doi:10.1080/13504622.2017.1360842.

NGSS Lead States. 2013. Next Generation Science Standards: For States, By States. Washington, DC: National Academies Press.

Paige, K., R. Hattam, and C. B. Daniels. 2015. “Two Models for Implementing Citizen Science Projects in Middle School." Journal of Educational Enquiry 14 (2): 4-17.

Pareja-Roblin, N. P., Schunn, C., \& McKenney, S. 2018. "What Are Critical Features of Science Curriculum Materials that Impact Student and Teacher Outcomes?,. Science Education, 102(2), 260-282

Phillips, T., N. Porticella, M. Constas, and R. Bonney. 2018. “A Framework for Articulating and Measuring Individual Learning Outcomes from Participation in Citizen Science.” Citizen Science: Theory and Practice 3 (2): 3.

Pilot, A., and A. M. W. Bulte. 2006. "The Use of "Contexts" as a Challenge for the Chemistry Curriculum: Its Successes and the Need for Further Development and Understanding." International Journal of Science Education 28 (9): 1087-1112. doi:10.1080/09500690600730737.

Rivet, A. E., \& Krajcik, J. S. (2004). “Achieving Standards in Urban Systemic Reform: An Example of a Sixth Grade Project-Based Science Curriculum,.. Journal of Research in Science Teaching, 41(7), 669-692

Rose, D. E. 2012. “Context-based Learning.” In Encyclopedia of the Sciences of Learning, edited by N. Seel, 799-802. New York: Springer.

Roseman, J. E., C. F. Herrmann-Abell, and M. Koppal. 2017. "Designing for the Next Generation Science Standards: Educative Curriculum Materials and Measures of Teacher Knowledge.” Journal of Science Teacher Education 28 (1): 111-141. doi:10.1080/1046560X.2016.1277598. 
Schwartz, A. T. 2006. “Contextualized Chemistry Education: The American Experience.” International Journal of Science Education 28 (9): 977-998. doi:10.1080/09500690600702488.

Shah, H. R., and L. R. Martinez. 2016. "Current Approaches in Implementing Citizen Science in the Classroom." Journal of Microbiology \& Biology Education 17 (1): 17-22. doi:10.1128/jmbe.v17i1.1032.

Songer, N. B. 2006. "BioKids: An Animated Conversation on the Development of Curricular Activity Structures for Inquiry Science." In The Cambridge Handbook of the Learning Sciences, edited by R. K. Sawyer, 355-369. New York: Cambridge University Press.

Tekkumru-Kisa, M., Stein, M. K., \& Schunn, C. 2015.“ A Framework for Analyzing Cognitive Demand and ContentPractices Integration: Task Analysis Guide in Science,. Journal of Research in Science Teaching, 52(5), 659-685

The Globe Program. (n.d.). Retrieved on from 20 May 2019, https:/www.globe.gov/do-globe/classroom-readyactivities/learning-activities

Thijs, A., and J. van den Akker. 2009. Curriculum in Development. Enschede, The Netherlands: SLO Netherlands Institute for Curriculum Development.

Trautmann, N. M., J. Shirk, J. Fee, and M. E. Krasny. 2012. "Who Poses the Question? Using Citizen Science to Help K-12 Teachers Meet the Mandate for Inquiry." In Citizen Science: Public Collaboration in Environmental Research, edited by J. L. Dickinson and R. Bonney, 179-190. Ithaca, NY: Cornell University Press.

Valero Haro, A., O. Noroozi, H. J. Biemans, and M. Mulder. 2019. "The Effects of an Online Learning Environment with Worked Examples and Peer Feedback on Students' Argumentative Essay Writing and Domain-specific Knowledge Acquisition in the Field of Biotechnology." Journal of Biological Education 53 (4): $390-398$. doi:10.1080/00219266.2018.1472132.

van den Akker, J. 2003. “Curriculum Perspectives: An Introduction.” In Curriculum Landscapes and Trends, edited by J. Van den Akker, W. Kuiper, and U. Hameyer, 1-10. Dordrecht, The Netherlands: Kluwer Academic Publishers.

Van Gog, T., F. Paas, and J. J. Merriënboer. 2004. "Process-oriented Worked Examples: Improving Transfer Performance through Enhanced Understandings." Instructional Science 32 (1/2): 83-98. doi:10.1023/B: TRUC.0000021810.70784.b0.

Yin, R. K. 2014. Case Study Research: Design and Methods. 5th edition. Thousand Oaks, California: Sage Publications,

Yu, K. C., S. C. Fan, and K. Y. Lin. 2015. "Enhancing Students' Problem-solving Skills through Context-based Learning." International Journal of Science and Mathematics Education 13 (6): 1377-1401. doi:10.1007/s10763014-9567-4.

Zangori, L., C. T. Forbes, and M. Biggers. 2013. "Fostering Student Sense Making in Elementary Science Learning Environments: Elementary Teachers' Use of Science Curriculum Materials to Promote Explanation Construction." Journal of Research in Science Teaching 50 (8): 989-1017. doi:10.1002/tea.21104.

Zoellick, B., S. J. Nelson, and M. Schauffler. 2012. "Participatory Science and Education: Bringing Both Views into Focus." Frontiers in Ecology and Environment 10 (6): 310-313. Citizen Science - new pathways to public involvement in research. doi:10.1890/110277. 